\title{
LOS ORÍGENES MEDIEVALES DEL NOMÁS AMERICANO
}

\author{
Eduardo Alcocer Rodríguez \\ José Luis Ramírez Luengo \\ Universidad Autónoma de Querétaro \\ dsd_lalo79@hotmail.com \\ joseluis.ramirezluengo@gmail.com
}

\begin{abstract}
RESUMEN: El adverbio nomás siempre ha sido considerado un rasgo identificador del español de América, caracterizado por emplearse en prácticamente todo el continente y presentar diversos valores, tales como, entre otros, refuerzo de adjetivos $y$ adverbios, enfatizador de verbos o simple matizador de la oración. Sin embargo, a pesar de su interés dialectal, no existen muchos estudios que profundicen en el origen de dicho elemento, de manera que es poco lo que se conoce acerca de los orígenes de su proceso de gramaticalización. Considerando, pues, lo anterior, este trabajo pretende analizar los usos medievales (siglos XII-XV) de nomás en España, con el propósito de comprobar si se encuentran ya ejemplos gramaticalizados de este elemento y, en este caso, describir cuál es su empleo y sus principales características morfosintácticas para, a partir de aquí, comprender los orígenes del nomás americano actual.

PALABRAS CLAVE: historia de la lengua española, español de América, morfosintaxis, nomás, Edad Media, gramaticalización.
\end{abstract}

\section{MEDIEVAL ORIGINS OF AMERICAN NOMÁS}

ABSTRACT: The adverbial locution nomás has always been considered a defining feature of American Spanish, appearing in basically the entire continent. It conveys several interpretations and uses, such as reinforcing adjectives and adverbs, emphasizing verbs, or as a plain sentence qualifier. However, despite its dialectal relevance, there aren't many studies looking deep into the origin of such element. Thus little is known about the first stages of its grammaticalization process. Considering the above, this study analyses the uses of nomás in medieval Spain (XII-XV centuries), with the purpose of verifying the existence of grammaticalized instances of this element and, in such a case, describe its usage and its main morphosyntactic characteristics, from which to better understand the origins of modern American nomás.

KEYWORDS: history of the Spanish language, American Spanish, morphosyntax, nomás, the Middle Ages, grammaticalization.

Recibido: 05/10/2017. Aceptado: 18/01/2018 


\section{Introducción}

Como es sobradamente conocido, el adverbio nomás ${ }^{1}$ constituye uno de los rasgos más identificadores de la morfosintaxis del español de América (Aleza 2010: 189), y se caracteriza no solo por estar presente en prácticamente todas las variedades del continente -entre ellas, Argentina, Chile, Colombia, Ecuador, Uruguay o Venezuela (Morínigo 1998: s.v. no; Frago Gracia y Franco Figueroa 2001: 113)-, sino también por contar con valores y significaciones muy variados, entre los que destacan, de acuerdo con Kany (1945: 72-79; 1970: 368-371) y el DPD (2005: s.v. no más, nomás), algunos como 'solamente', 'sin recelo', 'con confianza', 'apenas, tan pronto como', u otros usos como reforzador de adjetivos o adverbios, enfático junto a imperativos o suavizador de frases sin connotación real (ejemplos 1-3).

1) Hace dos días nomás que se fue (Kany 1970: 368)

2) Podemos ir a pie a mi finca, porque ahí nomás está (Kany 1970: 369)

3) Entrá nomás, sentate en ese asiento (Kany 1970: 370)

Por lo que se refiere a su interpretación sintáctica, cabe indicar que este elemento se considera un adverbio de foco de exclusión que deja "fuera de algún conjunto (expreso o tácito) al referente de la expresión denotada por su foco, de manera que informan de la inexistencia de alternativas distintas de las que se manifiestan" (NGLE 2009: 40.9a). Esta idea de nomás como focalizador ha sido retomada en otros trabajos en los que destaca su carácter de comparativo de exclusividad o exhaustividad (Kovacci 1999: §11.7.1.; Tognola 2010: 2-3; Gutiérrez González 2011: 48-50), además de su capacidad de marcar, en su esquema más básico, un límite -en origen de cantidad- que no se debe sobrepasar (García Pérez 2013: 336).

Frente a su descripción sincrónica, los estudios dedicados a la historia de este elemento son mucho más escasos, y se reducen a plantear la hipótesis de su posible origen en la estructura y no más (Melander 1920: 79-84) o indicar su presencia en España durante los Siglos de Oro (Kany 1945: 72; Hildebrandt 1961: 322-323; Frago Gracia 2007: 218; Ramírez Luengo 2007: 78-79; Espinosa Elorza 2014: 1015), si bien también se pueden rastrear algunos ejemplos en épocas anteriores como es el siglo XIII (García Pérez 2013: 337) (ejemplo 4):

1. A partir de ahora, se utiliza la grafía unida, nomás, para denominar al adverbio que permite la lectura gramaticalizada actual, mientras que se reserva no más para aquellos ejemplos en los que tal lectura no es posible. 
4) El candelero que vos dixiemos que fuera puesto en la cámara de los sacrificios después de la entrada de la tienda, e de noche ardién ý VII lámpadas, e de día cuatro nonmás (c. 1275; Alfonso X, General Estoria)

Se hace del todo necesario, por tanto, desarrollar nuevas investigaciones diacrónicas sobre este peculiar adverbio que sirvan para responder muchas de las cuestiones que aún no se conocen acerca de su historia, entre las que es posible destacar algunas como, por ejemplo, en qué momento se produce la gramaticalización de no más > nomás, cuál es el comportamiento morfosintáctico prototípico en sus orígenes y por medio de qué procesos se llega a la multiplicidad de usos y valores que, como señala Kany (1945: 72-79; 1970: 368-371), presenta en el momento actual.

Antes de continuar, conviene señalar que el presente artículo se organiza de la siguiente manera: tras el breve estado de la cuestión (sección 1) y unas observaciones relacionadas con el corpus y la metodología de trabajo (sección 2), se pasa a la presentación de los datos y su análisis de acuerdo con los criterios que se mencionarán a continuación (sección 3), para terminar con unas conclusiones (sección 4) donde se recapitulan todas las informaciones expuestas en el apartado anterior y se responde de forma explícita las preguntas de investigación que se establecen como objetivos del estudio, esto es, si existe un nomás gramaticalizado en la época medieval, en qué momento se descubren por primera vez estos usos y cuál es su comportamiento sintáctico más frecuente de acuerdo con los criterios ya expuestos.

\section{Metodología y corpus analizado}

Partiendo, pues, de la situación inmediatamente descrita, y dado el desconocimiento que existe acerca de los orígenes y la evolución de nomás, el presente trabajo pretende aportar unos primeros datos que contribuyan a conocer mejor el desarrollo diacrónico de este elemento morfosintáctico del español, muy especialmente en lo que tiene que ver con sus orígenes. Así, los objetivos de este trabajo se pueden cifrar en dos: por un lado, confirmar con datos cuantitativos que, como señala García Pérez (2013: 336-337), existe un nomás gramaticalizado durante la Edad Media, así como indicar desde cuándo se registra en los textos; por otro, describir su uso sintáctico en este periodo de acuerdo con diversos parámetros, en concreto: I) casos gramaticalizados por millón de palabras; II) estructuras sintácticas en las que aparece nomás; III) ele- 
mento al que este afecta; IV) presencia de un cuantificador en el sintagma; V) posición de nomás respecto al elemento afectado; y VI) adyacencia de ambos ${ }^{2}$.

En cuanto al corpus de análisis, se ha optado por emplear para el presente estudio el Corpus Diacrónico del Español (CORDE) con un rango temporal que cubre toda la Edad Media, desde el siglo XII al siglo XV, y con la especificidad geográfica España, lo que ha dado un resultado total de 147 apariciones gramaticalizadas $^{3}$; no se establecen especificidades tipológicas por el alcance exploratorio del análisis, pero también por la escasez de ejemplos registrados en CORDE, que aconseja no restringir aún más las condiciones de búsqueda ${ }^{4}$ Por otro lado -y aunque pueda parecer evidente-, es importante señalar que en las búsquedas se toman en cuenta exclusivamente aquellos ejemplos en los que los dos formantes de nomás, no(n) y más están adyacentes entre sí, pues solo en tal contexto se produce su gramaticalización ${ }^{5}$.

Desde el punto de vista metodológico, parece también relevante mencionar que la detección de los casos de nomás gramaticalizado no ha sido sencilla, habida cuenta de la ambigüedad que en ocasiones presenta su interpretación y, por tanto, las dificultades que se plantean para determinar si algunos ejemplos concretos se deben entender como gramaticalizados o no gramaticalizados, esto es, un caso de nomás (dame cuatro nomás) o de no más (dame cuatro, no más) ${ }^{6}$.

2. La selección de estos parámetros de análisis responde a dos criterios fundamentales: en primer lugar, al hecho de que en el momento actual algunos sirvan para establecer diferencias dialectales en el uso de nomás -II, IV o V-(Kany 1945:72-79; 1970: 368-371); así mismo, al que muchos de ellos guarden relación con fenómenos que tienen lugar en los procesos de gramaticalización (Company 2012: 687-688), tales como, entre otros, el aumento de uso (I) y libertad sintáctica (II) o la generalización contextual (III, IV, V, VI).

3. En concreto, 55 del siglo XIII, 12 del siglo XIV y 80 del siglo XV.

4. Teniendo en cuenta el carácter marcadamente coloquial de nomás en el momento actual, es posible que tal escasez de apariciones en el corpus se pueda poner en relación con las tipologías textuales que se recogen en él durante la Edad Media, caracterizados por cierto alejamiento del polo de la inmediatez comunicativa (Oesterreicher 2004: 752), donde, como se ha indicado ya, este elemento es especialmente frecuente. Cabe indicar, con todo, que tal escasez no parece ser algo específico del repositorio académico: a manera de ejemplo, una búsqueda detallada de nomás en CODEA no ofrece ni un solo caso del mismo en la época medieval, algo que probablemente se explique, una vez más, a causa de las tipologías textuales que componen este corpus.

5. En este sentido, las limitaciones de CORDE y su falta de lematización obligó a que la búsqueda de los ejemplos se llevara a cabo considerando todas las posibles grafías del elemento que se va a estudiar -en concreto, no más, No más, no mas, No mas, nomás, Nomás, nomas, Nomas, non más, Non más, non mas, Non mas, nonmás, Nonmás, nonmas y Nonmas-, con el propósito de obtener todas las apariciones presentes en el corpus.

6. En este sentido, señala García Pérez (2013: 336) que, como resultado del lento proceso de gramaticalización que experimenta esta estructura, "no siempre es fácil determinar cuándo desaparece el valor puramente comparativo y se adquiere el valor de focalización"; de hecho, en casos de esta naturaleza es únicamente la prosodia la que puede establecer la diferencia entre los dos usos y facilitar su interpretación 
Teniendo en cuenta, pues, tales dificultades, se ha decidido emplear en estas páginas un criterio conservador de selección que permita evitar la sobreinterpretación de los datos, de manera que se ha optado por tomar como casos gramaticalizados aquellas apariciones de no(n)más que presentan en el corpus características morfosintácticas y semánticas que se pueden asimilar a las que este elemento presenta en la sincronía actual.

\section{Análisis de los datos}

De este modo, el análisis de los datos que ofrece el corpus considerado en estas páginas permite responder de una manera satisfactoria las cuestiones que se plantean más arriba como preguntas de investigación $\mathrm{y}$, por tanto, obtener a partir de aquí datos de notable relevancia para la más completa comprensión de los orígenes y los usos medievales del elemento nomás.

\subsection{Fecha de gramaticalización}

Así pues, conviene comenzar este análisis intentando establecer la fecha de aparición de los primeros casos de nomás gramaticalizado, y a este respecto se hace necesario señalar que la revisión detallada del corpus evidencia la inexistencia de tal elemento en el siglo XII: en efecto, la búsqueda en los fondos de CORDE de tal centuria no ofrece ningún ejemplo en el que la aparición conjunta de los elementos $n o(n)$ y más permita la lectura gramaticalizada propia del español americano actual, si bien es importante señalar la presencia, ya en esta época, de estructuras cercanas a las oraciones comparativas ${ }^{7}$ en las que aparecen los elementos que, con el paso del tiempo, darán lugar al adverbio gramaticalizado nomás. En concreto, tales estructuras son las siguientes: a) no(n) verbo más; b) no(n) verbo más + segundo término; c) no(n)más, en este caso siempre introducido por la conjunción copulativa $y$, tal y como señalaba Melander en su estudio (1920: 77-84) (ejemplos 5, 6, 7).

inequívoca, si bien esta cuestión -como acertadamente recuerda Espinosa Elorza (2014b: 2239-2240)resulta notablemente compleja de analizar en textos antiguos por la falta de signos de puntuación o por su escasa fiabilidad, de manera que la única herramienta disponible para la interpretación cabal de estos ejemplos es el propio contexto documental.

7. Según postula Freire Llamas (2014: 3871), solo las construcciones en que se encuentran las dos partes de la comparación o de la escala pueden considerarse comparativas, por lo que las estructuras que se van a analizar en estas páginas no cumplen obligatoriamente en todos los casos las condiciones necesarias para considerarlas como tales.

8. Teniendo en cuenta el paralelismo existente entre no(n) verbo más y no(n) más, parece lógico pensar que la estructura no(n) verbo más + segundo término tiene también que acompañarse de su corre- 
5) Dixo Pharaon: "Tuelte de sobre mi, e non vengas mas ante mi" (c. 1200; Almerich, La Fazienda de Ultra Mar) ${ }^{9}$

6) Totus homo qui arras ouiere a dar non det mas de .XX. morabetinos (11791184, Anónimo, Fuero de Uclés)

7) Las aldeas que oujeren dehesas cada una dellas por si den cadanno fasta çinco deheseros \& non mas (1196; Anónimo, Fuero de Soria)

Frente a esta situación inmediatamente descrita, el siglo XIII -y más en concreto su segunda mitad- presenta una importante diferencia, pues es precisamente ahora cuando es posible detectar los primeros ejemplos que habilitan una interpretación ya gramaticalizada de nomás, esto es, con un valor de focalizador exclusivo/exhaustivo con interpretación semántica de límite (García Pérez 2013: 336), semejante a la que actualmente presenta en el español americano (Kovacci 1999: §11.7.1.; Tognola 2010: 2-3; Gutiérrez González 2011: 48-50) (ejemplos 8, 9). Esto no solo corrobora los orígenes medievales de este elemento propuestos por García Pérez (2013: 336-337), sino que además permite datar su aparición -o, más bien, su registro por escrito- a lo largo del Doscientos, concretamente en plena época alfonsí, conclusión que parece verse confirmada, así mismo, por el hecho de que, a partir de ese momento y durante toda la Edad Media, se registren apariciones del elemento estudiado de forma ininterrumpida (ejemplos 10, 11).

8) La quarta es pintada de muchas colores. La quinta es de dos colores no mas. Et de cada una destas fablaremos en este libro en el logar do conuiene (c. 1250; Alfonso X, Lapidario)

9) Et si fuer el grado de ambas en la longura uno; cata si a ladeza la una dellas non mas. \& aquella ladeza es lo que a entrellas del çerco mayor (c. 1277; Rabí Zag, Libros de la lámina universal)

10) En aquella villa misma avía otro omne muy más onrado et más rico que su padre, et avía una fija nonmás, et era muy contraria de aquel mancebo (13251335; Juan Manuel, El Conde Lucanor)

11) Dezian los samaritaños que era el lugar do se devia adorar Dios \& los judios dezian que no mas en Hierusalem, como pareçe en el .iiii. capitulo de Sant Juan (1494; Fray Vicente de Burgos, Traducción de El Libro de Propietatibus Rerum)

\footnotetext{
lato sin verbo, no(n)más + segundo término; sin embargo, las búsquedas en el corpus del siglo XII no ofrecen ni un solo ejemplo de tal estructura, que -como se dirá más adelante- solo comienza a aparecer, de forma muy esporádica, a partir de la centuria siguiente.

9. Dadas las especiales características de este texto, se ha consultado la edición de Arbesú (2011) para corroborar la lectura de CORDE; no se discute aquí, por no ser de especial relevancia para el análisis, la fecha de composición de la obra, que este autor localiza en torno a 1220-1230.
} 


\subsection{Casos gramaticalizados por millón de palabras}

Esta presencia ininterrumpida que se acaba de ejemplificar se ve corroborada, por otro lado, con los datos cuantitivos que aparecen en la tabla 1, donde se presenta la frecuencia de aparición de nomás gramaticalizado por millón de palabras:

Tabla 1. Frecuencia de aparición de no(n)más por millón de palabras

\begin{tabular}{|l|l|l|l|l|}
\hline Frecuencia & \multicolumn{1}{c|}{ XII } & \multicolumn{1}{c|}{ XIII } & \multicolumn{1}{c|}{ XIV } & \multicolumn{1}{c|}{ XV } \\
\hline Palabras en el corpus & 451,828 & $8,877,373$ & $8,838,418$ & $22,241,261$ \\
\hline nomás/millón & 0 & 6.2 & 1.36 & 3.6 \\
\hline
\end{tabular}

Se descubre, por tanto, que de la ya mencionada inexistencia de ejemplos en el siglo XII se asciende a una frecuencia de aparición relativamente elevada, de 6.2 casos por millón de palabras, para pasar posteriormente, en los siglos XIV y $\mathrm{XV}$, a ratios mucho más escasas, de 1.36 y 3.6 ejemplos con lectura gramaticalizada por cada millón de palabras respectivamente. Así pues, y más allá de las oscilaciones que se descubren en cada siglo ${ }^{10}$, salta a la vista la básica continuidad en cuanto al empleo de nomás durante toda la Edad Media, con unos porcentajes que, si bien se ven modificados de siglo en siglo, en todo caso resultan constantes en lo que tiene que ver con su baja aparición, algo que no sorprende si se considera el carácter oral/coloquial que, según se ha dicho ya, caracteriza a nomás (Kany 1970: 368).

\subsection{Estructuras sintácticas con nomás}

Teniendo ahora en cuenta los contextos en los que se puede generar la gramaticalización de nomás -en concreto, no(n)más y no(n)más + segundo término-, es interesante destacar que ambas estructuras se descubren en la época medieval y ambas presentan posibles lecturas gramaticalizadas, si bien su frecuencia de aparición es muy diferente, como se aprecia en la tabla 2:

10. Y que se pueden deber, entre otros factores, a la misma tipología textual de que se compone el corpus de CORDE, que presenta importantes variaciones a través de los siglos; de ahí la importancia de atender en posteriores análisis el factor tipológico como forma de ofrecer una visión más precisa de la aparición y empleo de esta forma en la época medieval. 
Tabla 2. Estructura no(n)más vs. estructura no(n)más $+2^{\circ}$ término

\begin{tabular}{|l|r|r|r|}
\hline Estructuras & \multicolumn{1}{|c|}{ XIII } & \multicolumn{1}{|c|}{ XIV } & \multicolumn{1}{c|}{ XV } \\
\hline Nomás & $54(98.2 \%)$ & $12(100 \%)$ & $79(98.7 \%)$ \\
\hline Nomás + de/que & $1(1.8 \%)$ & $0(0 \%)$ & $1(1.3 \%)$ \\
\hline Total de casos & 55 & 12 & 80 \\
\hline
\end{tabular}

Los datos anteriores demuestran de forma más que evidente que, de ambas posibilidades, la construcción no(n)más (ejemplos 12,13) constituye la prototípica durante toda la Edad Media a la hora de actuar con valor focalizador, pues su frecuencia de aparición es siempre superior al $98 \%$ de los casos, mientras que la otra estructura, no(n)más $+2^{\circ}$ término (ejemplos 14, 15), si bien presente así mismo en este momento, resulta puramente anecdótica, al contar únicamente con atestiguaciones puntuales a lo largo de todo el periodo analizado ${ }^{11}$.

12) Et quando passaren los primeros ueynte dias con sus noches, tomaras plomo \& faras dell figura de oueia, el cuerpo della no mas (1256; Alfonso X, Picatrix)

13) Pero digo yo que si le tomare dolencia \& seyendo de veynte años nonmas y aya menester sangria \& purgacion: deuemoslo fazer (c. 1381-1418; Anónimo, Sevillana medicina de Juan de Aviñón)

14) E commo se conosçieron muy bien don Hector e aqueste nonmas que se vieron, aguiijaron los cauallos muy de rrezio vno contra otro e fueron se ferir (c. 1270; Anónimo, Historia troyana en prosa y verso)

15) Visto esto, mandó cessar el Almirante la fiesta del tañer y bailar, y sacar sobre cubierta algunas ballestas, y tiralles con dos ballestas, no más de para assombrallos (1498; Anónimo, Relación del Tercer Viaje de Colón)

11. La aparición de un único ejemplo de tal estructura en el siglo XIII permitiría pensar que se trata de un mero error de transmisión textual, producto de la copia en un momento posterior de la obra donde se descubre; sin embargo, Fernández-Ordóñez (2004: 391) señala el Libro del Judizio de las estrellas como uno de los escasos originales alfonsíes que se conservan, de manera que esta interpretación resulta improbable. De este modo, y dado que a partir del siglo XV casos semejantes van a aparecer de manera regular, es necesario preguntarse si el ejemplo mencionado corresponde a una posibilidad de la lengua de la época que no tiene más reflejo escrito que este caso o se trata de un uso puramente circunstancial que está determinado por diversos factores difíciles de precisar y que posteriormente tendrá un desarrollo más amplio. En esta misma línea, es también importante señalar lo tardío del ejemplo del siglo XV, 1498, que parece anunciar la situación de la centuria posterior, en que hay una explosión en el empleo de esta construcción. 


\subsection{Elementos afectados por nomás}

Centrando ahora el análisis en el comportamiento sintáctico de la estructura más frecuente - esto es, de no(n)más-, es interesante preguntarse en primer lugar cuáles son las categorías morfológicas que se ven afectadas por la forma estudiada y qué posibilidades existen al respecto durante la época medieval; en concreto, los datos que arroja el corpus son los siguientes (tabla 3$)^{12}$ :

Tabla 3. Elemento afectado por no(n)más gramaticalizado

\begin{tabular}{|l|r|r|r|}
\hline Elemento afectado & \multicolumn{1}{|c|}{ XIII } & \multicolumn{1}{|c|}{ XIV } & \multicolumn{1}{|c|}{ XV } \\
\hline Sustantivo $^{13}$ & $53(98.1 \%)$ & $12(100 \%)$ & $79(100 \%)$ \\
\hline Verbo conjugado & $1(1.9 \%)$ & $0(0 \%)$ & $0 \%$ \\
\hline Total de casos & 54 & 12 & 79 \\
\hline
\end{tabular}

Una vez más, los datos exponen una situación muy estable y virtualmente idéntica a lo largo de los tres siglos: dejando aparte un caso de afectación a un verbo conjugado en el siglo XIII (ejemplo 16), el elemento que se ve afectado por nomás es siempre un sustantivo, que constituye, así, el contexto por excelencia en que se usa la forma gramaticalizada durante el periodo medieval (ejemplos 17, 18):

16) Yo digo que la cabeça nin la cola non puian nin menguan mas que esfuerçan \& enflaquecen non mas. (1254-1260; Alfonso X, Judizios de las estrellas)

17) Que quando el abat oviere de dar alcaldes e merino en la villa de Sant Fagund, que llame de cada collacion un omne bueno e de buena fama a su casa non mas. (1345; Anónimo, sentencia de Alfonso XI)

18) Estas señales son las mortales en aquellos que han tomado ponçoña: quando se esconde la pupila del ojo \& paresce lo blanco del ojo no mas (1495; Anónimo, Gordonio)

12. Cabe indicar que para determinar el elemento al que afecta nomás en la oración se utiliza la prueba de la paráfrasis con ser+relativo (Moreno Cabrera 1999: 65.1): Tiene un hijo nomás > Es un hijo nomás lo que tiene.

13. Téngase en cuenta que bajo esta categoría se agrupan los sustantivos presentes tanto en una frase nominal (ejemplo I) como en una frase preposicional (ejemplo II), siempre y cuando tal sustantivo constituya el núcleo de dicho sintagma:

I) A ellos los dizen muyt bref. que non y fazen si non las figuras de las cruzes non mas (1259; Alfonso X, Libro de las Cruces)

II) Céuenlas d'esta manera fasta que sean sanas. E si ouieren la flaqueza en las alas no más, e ge lo uieren quando uolaren [...], mégenles sobre las alas (1250; Abraham de Toledo, Moamín) 


\subsection{Presencia/ausencia de cuantificación}

Así mismo, y en estrecha relación con lo anterior, también la presencia o ausencia de cuantificación en el sintagma afectado por nomás se presenta como un factor de interés a la hora de describir el comportamiento sintáctico de este elemento en los siglos medievales; por lo que se refiere a esta cuestión, los datos aparecen recogidos en la tabla que se presenta a continuación (tabla 4):

\section{Tabla 4. Presencia de cuantificación en el sintagma afectado por no(n)más}

\begin{tabular}{|l|r|r|r|}
\hline Cuantificación & \multicolumn{1}{|c|}{ XIII } & \multicolumn{1}{|c|}{ XIV } & \multicolumn{1}{l|}{ XV } \\
\hline Explícita & $39(72.2 \%)$ & $12(100 \%)$ & $53(67.1 \%)$ \\
\hline No explícita & $15(27.8 \%)$ & $0(0 \%)$ & $26(32.9 \%)$ \\
\hline Total de casos & 54 & 12 & 79 \\
\hline
\end{tabular}

De este modo, se evidencia que la presencia de una cuantificación explícita ${ }^{14}$ en el sintagma afectado por nomás resulta la opción predominante, al presentar unos porcentajes notablemente elevados en todos los periodos considerados en este estudio (ejemplos 19, 20), si bien eso no oculta que el caso contrario -es decir, la falta de cuantificación (ejemplos 21, 22)-, es también una posibilidad presente desde el mismo siglo XIII que, además, se mantiene de forma estable durante toda la Edad Media ${ }^{15}$.

19) Abenjahaf dixo a los moros de la çibdad que atendiessen tres dias non mas (c.1325; Anónimo, Crónica de veinte reyes)

14. Se entiende por cuantificación explícita en este caso tanto la presencia de un numeral en el sintagma (ejemplo III) como la aparición de un nombre propio (ejemplo IV), en el supuesto de que la entidad a la que se refiere tal nombre propio es única y, por tanto, está ya intrínsecamente cuantificada.

III) Porque tura en algunas mujeres la expulsion del mestruo tres dias; en otras seys; en otras siete. [R] esponde vnas hay que tienen mas calor que otras: \& acostumbra de turar tres dias no mas; en las donzellas \& mujeres muy moças (c. 1400-1500; Anónimo, Compendio de la humana salud)

IV) Sin Alhara Nueva, que tiene maestro Jacobo et non lo dize en el privilegio que el tiene, si non de Benihalel non mas. Et mando el Rey que lo que el tiene demas, que en el privilegio non dize, que lo partiessemos (1257-1271; Anónimo, Repartimiento de Murcia)

15. No se puede pasar por alto que el siglo XIV constituye una excepción a lo que se acaba de mencionar sobre esta supuesta estabilidad; sin embargo, y como se ha indicado anteriormente al hablar sobre la frecuencia de uso, esta centuria presenta en el corpus diferencias muy marcadas respecto a los demás siglos de la Edad Media, algo que quizá guarde relación con las tipológicas de los textos del siglo XIV que aparecen en el repositorio de la RAE. 
20) Es de saber que los fonderos son de acostunbrar que una vez non mas rodeen la fonda contra la cabeça quando lançan con ella la piedra (1454; Fray Alonso de San Cristóbal, Libro de Vegecia de la caballería)

21) E si fueren en los succedentes; significa que el su fallamiento. \& el su cobramiento se tarda mucho. \& esta signification \& este iudizio es. propria miente a este capitol non mas (1254-1260; Alfonso X, Judizios de las estrellas)

22) Todo lo que es fuera desto de los laujm que non tienen obra el daño que dellos viene es poco \& non puede ser de se guardar dellos por que son palabras non mas (1419-1432; Pedro de Toledo, Guía de los Perplejos de Maimónides)

\subsection{Posición de nomás}

Pasando ahora a la colocación sintáctica que presenta nomás en relación con el elemento al que afecta, se hace preciso llevar a cabo el análisis de esta cuestión desde dos puntos de vista complementarios: por un lado, describiendo su posición -bien antepuesto, bien pospuesto- respecto del sintagma al que acompaña; por otro, atendiendo a su adyacencia a este mismo sintagma.

En cuanto a la primera de las cuestiones que se han mencionado, los datos que ofrece el corpus para los distintos siglos medievales se han clasificado de acuerdo con un criterio binario (antepuesto/pospuesto al elemento afectado), tal y como se descubre en la tabla 5:

Tabla 5. Posición de no(n)más respecto al elemento al que afecta

\begin{tabular}{|l|r|r|r|}
\hline Posición & \multicolumn{1}{|c|}{ XIII } & \multicolumn{1}{|c|}{ XIV } & \multicolumn{1}{c|}{ XV } \\
\hline Posposición & $54(100 \%)$ & $11(91.7 \%)$ & $76(96.2 \%)$ \\
\hline Anteposición & $0(0 \%)$ & $1(8.3 \%)$ & $3(3.8 \%)$ \\
\hline Total de casos & 54 & 12 & 79 \\
\hline
\end{tabular}

De este modo, los datos demuestran, en primer lugar, una clara preferencia en todo el periodo analizado por la posposición de nomás al elemento que se ve afectado por él, con unos porcentajes siempre superiores al 90\% (ejemplos 23, 24); es importante mencionar, con todo, que a partir del siglo XIV comienzan a aparecer esporádicamente casos de anteposición (ejemplos 25,26$)$ que, si bien resultan claramente minoritarios, no carecen de importancia, dado que parecen prefigurar algunas de las posibilidades sintácticas que ofrece el nomás actual en determinadas variedades diatópicas americanas como México (DPD 2005: s.v. no más, nomás). 
23) Bien te puede complir en saber estas cuerdas partidas por medio que sepas las cuerdas que son dun grado fata XC grados nonmas. (1276-1277; Alfonso X, Cánones de Albateni)

24) Por que salieron commo diz \& traere a uos otros para mj \& esa estança terrible de Synay. fue vn dia nonmas (1419-1432; Pedro de Toledo, Guía de los perplejos de Maimónides)

25) Et nonmas don Iohaan poso con todos los suyos en la moreria, et el infant don Pedro con todos los suyos en el raual (1376-1391; Juan Fernández de Heredia, Gran Crónica de España, III)

26) Y si dices, ¿cuándo Dios la sacó de Adán, si la sacó del hueso mondo o de la carne? digo que nomás con carne y pellejo (1468; Fray Martín de Córdoba, Jardín de nobles doncellas)

Por lo que se refiere a la segunda de las cuestiones, la adyacencia entre nomás y el elemento afectado, una vez más se descubre en el corpus una situación caracterizada por la variación, en este caso en forma de convivencia de ambas posibilidades, tal y como se evidencia en la tabla 6 :

Tabla 6. Adyacencia de no(n)más al elemento afectado

\begin{tabular}{|l|r|r|r|}
\hline Adyacencia & \multicolumn{1}{|c|}{ XIII } & \multicolumn{1}{|c|}{ XIV } & \multicolumn{1}{c|}{ XV } \\
\hline Adyacente & $53(98.1 \%)$ & $10(83.3 \%)$ & $74(93.7 \%)$ \\
\hline No adyacente & $1(1.9 \%)$ & $2(16.7 \%)$ & $5(6.3 \%)$ \\
\hline Total de casos & 54 & 12 & 79 \\
\hline
\end{tabular}

Así pues, y al igual que sucedía en el caso anterior, a lo largo del periodo medieval se descubre también en este punto un comportamiento sintáctico claramente privilegiado: en efecto, los datos demuestran que la adyacencia, con porcentajes de en torno al 90\%, supone la posibilidad predominante (ejemplos 27, 28), si bien es necesario resaltar de nuevo la aparición circunstancial de nomás como no adyacente al elemento afectado (ejemplos 29,30), por cuanto se trata de una posibilidad que, según parece, se va a afianzar a lo largo del tiempo hasta llegar a la situación actual, en la que constituye una opción relativamente frecuente en el empleo de este elemento (Kany 1970: 368, 370).

27) E sabet que el priscal non se puede llantar del arbol sinon de sus huesos non mas e non toman del rramo desgajado nin fijo nin estaca para poner (c. 1300; Anónimo, Tratado de agricultura de Ibn Bassal) 
28) E ellos havían embiado con Sarus todos los sobrinos de Polus con dos mil cavalleros que quedaron con ellos. E los arçobispos con tres mil no más (c. 1430; Pedro de Corral, Crónica del rey don Rodrigo)

29) Los menbrillos se deuen llantar desta guisa. Tomen de los verdugos que son para llantar e fan los foyos, que aya en cada foyo dos palmos en fondo non mas (c. 1300; Anónimo, Tratado de agricultura de Ibn Bassal)

30) Vayamos nos serujr al buen Rey don fernand, que tres dias ha nonmas para complir se el plazo (c. 1400; Anónimo, Mocedades de Rodrigo)

\section{Conclusiones}

De este modo, el análisis que se ha llevado a cabo a lo largo de estas páginas permite extraer ya una serie de conclusiones que responden a las preguntas de investigación planteadas en el segundo apartado y que tienen que ver con la existencia de un nomás gramaticalizado en la época medieval, el momento de aparición de tal elemento en los textos castellanos y su comportamiento sintáctico prototípico.

Por lo que toca a la primera cuestión, se puede concluir que la gramaticalización de nomás es sin duda un fenómeno propiamente medieval, habida cuenta de que el corpus aquí analizado ofrece para este periodo histórico una cierta abundancia de ejemplos que muestran un comportamiento similar $-\mathrm{O}$ al menos muy cercano- al que se descubre en la actualidad. Este hecho no solo sirve para confirmar la cronología señalada por García Pérez (2013: 336-337) para la aparición del nomás gramaticalizado, sino que además enriquece sus datos con nuevas atestiguaciones que evidencian el uso más o menos frecuente de este elemento en la época mencionada.

Pasando ya a la segunda de las cuestiones, este análisis permite también matizar la cronología que se acaba de proponer y plantear que el desarrollo del proceso de gramaticalización -o más bien, su paso a los textos escritos- tiene lugar en pleno siglo XIII, y más específicamente en su segunda mitad: en efecto, el análisis desarrollado sobre la documentación del siglo XII no registra ni un solo ejemplo de nomás que presente una lectura gramaticalizada, misma que comienza a aparecer en la centuria siguiente, de manera que por el momento es posible postular que es en la época alfonsí cuando este fenómeno hace su aparición en la diacronía del español.

En cuanto al comportamiento sintáctico de este elemento, se debe señalar que se descubre una situación prácticamente idéntica durante los tres siglos 
medievales, caracterizada por los siguientes aspectos: a) predominio de nomás frente a nomás de/que; b) afectación a un sustantivo con cuantificación explícita; c) posposición al elemento afectado; y d) adyacencia a tal elemento. Es posible sostener, por tanto, que desde el punto de vista sintáctico el nomás gramaticalizado presenta en los siglos XIII, XIV y XV una gran estabilidad, al ofrecer de forma mayoritaria un comportamiento común y constante ${ }^{16}$, si bien esto no debe ocultar la presencia, ya en estos momentos, de algunos casos divergentes frente a la generalidad inmediatamente descrita ${ }^{17}$ que no solo anticipan determinados usos de nomás que se van a intensificar en fechas posteriores a las de este análisis, sino que a la vez -y como bien señala Kany (1970: 368) al hablar de determinados ejemplos áureos- permiten vislumbrar la variedad y multiplicidad de posibilidades sintácticas que van a caracterizar su empleo moderno en las diversas variedades americanas que actualmente lo utilizan.

\section{Bibliografía}

ALEZA, M. (2010). "Morfología y sintaxis. Observaciones gramaticales de interés en el español de América" en La lengua española en América: normas y usos actuales. (Coords. M. Aleza y J. M. Enguita Utrilla). Valencia: Universitat de València: 95-224.

ARBESÚ, D. (2011). La Fazienda de Ultramar <http://www.lafaziendadeultramar.com>. (Acceso enero 2018).

COMPANY, C. (2012). "Historical morphosyntax and grammaticalization" en The handbook of Hipanic Linguistics. (Eds. J. I. Hualde, A. Olarrea y E. O’Rourke). Oxford: Wiley-Blackwell: 673-710.

CODEA. GRUPO DE INVESTIGACIÓN TEXTOS PARA LA HISTORIA DEL ESPAÑOL (2018). CODEA+2015. Corpus de documentos españoles anteriores a $1800<\mathrm{http}: / /$ corpuscodea.es $>$ (Acceso enero 2018).

16. Queda por analizar, por supuesto, si desde el punto de vista semántico y pragmático también se descubre durante la Edad Media una situación de estabilidad semejante, si bien esa cuestión -así como otras fundamentales para entender la historia de este elemento, entre las que destacan, por ejemplo, el momento de desaparición de nomás en España o las causas y los procesos que producen los variados usos americanos actuales - queda para posteriores trabajos que trasciendan la etapa medieval considerada en estas páginas.

17. Divergencias, además, que se producen en todos los factores analizados, al descubrirse apariciones esporádicas de nomás de/que $+2^{\circ}$ término (ejemplos 14, 15), casos de afectación a elementos no sustantivos (ejemplo 16), aparición con sustantivos no cuantificados (ejemplos 21, 22) o, desde el punto de vista de su colocación sintáctica, presencia de anteposición y casos de no adyacencia entre nomás y el elemento afectado (ejemplos 25, 26 y 29, 30 respectivamente). 
CORDE. REAL ACADEMIA ESPAÑOLA (2017). Corpus Diacrónico del Espa$\tilde{n}$ ol $<$ http://corpus.rae.es/cordenet.html $>$. (Acceso julio-agosto 2017).

DPD. REAL ACADEMIA ESPAÑOLA/ASALE (2005). Diccionario panhispánico de dudas. Madrid: Santillana.

ESPINOSA ELORZA, R. M. (2014). "Adverbios de cantidad, foco, polaridad y modalidad" en Sintaxis histórica de la lengua española. Tercera parte: Preposiciones, adverbios y conjunciones. Relaciones internacionales (3 vols.). (Dir. C. Company). México D.F.: Fondo de Cultura Económica - Universidad Nacional Autónoma de México: 939-1117.

ESPINOSA ELORZA, R. M. (2014b). “Coordinación y subordinación. Panorama general, relaciones diacrónicas básicas y nexos” en Sintaxis histórica de la lengua española. Tercera parte: Preposiciones, adverbios y conjunciones. Relaciones internacionales (3 vols.). (Dir. C. Company). México D.F.: Fondo de Cultura Económica - Universidad Nacional Autónoma de México: 22312336.

FERNÁNDEZ-ORDÓÑEZ, I. (2004). “Alfonso X el Sabio en la historia del español" en Historia de la lengua española. (Coord. R. Cano Aguilar). Barcelona: Ariel: 381-422.

FRAGO GRACIA, J. A. (2007). "Tradición e innovación en el español americano de la Independencia”. Romance Philology 61: 147-191.

FRAGO GRACIA, J. A. y FRANCO FIGUEROA, M. (2001). El Español de América. Cádiz: Universidad de Cádiz.

FREIRE LLAMAS, A. (2014). "Oraciones comparativas" en Sintaxis histórica de la lengua española. Tercera parte: Preposiciones, adverbios y conjunciones. Relaciones internacionales (3 vols.). (Dir. C. Company). México D.F.: Fondo de Cultura Económica - Universidad Nacional Autónoma de México: 3841-3904.

GARCÍA PÉREZ, R. (2013). "La evolución de los adverbios de foco en español: adverbios focalizadores de exclusión, inclusión y aproximación" en Los adverbios con función discursiva. Procesos de formación y evolución. (Ed. M. P. Garcés Gómez). Madrid: Iberoamericana; Frankfurt: Vervuert: 317-388.

GUTIÉRREZ-GONZÁLEZ, Y. (2011). “¿Operadores focales exhaustivos nomás?". Cuadernos de ALFAL 3: 42-59.

HILDEBRANDT, M. (1961). La lengua de Bolívar. I, Léxico. Caracas: Universidad Central de Venezuela.

KANY, Ch. E. (1945). "American Spanish nomás". Hispanic Review 13: 72-79. KANY, Ch. E. (1970). Sintaxis Hispanoamericana. Madrid: Gredos. 
KOVACCI, O. (1999). "El adverbio" en Gramática descriptiva de la lengua española. (3 vols.). (Coords. I. Bosque y V. Demonte). Madrid: EspasaCalpe: $705-786$.

MELANDER, J. (1920). "L'origine de l'espagnol no más au sens de seulement". Studier i Modern Sprakvetenskap 7: 77-84.

MORENO CABRERA, J. C. (1999). "Las funciones informativas: las perífrasis de relativo y otras construcciones perifrásticas" en Gramática descriptiva de la lengua española. (3 vols.). (Coords. I. Bosque y V. Demonte). Madrid: Espasa-Calpe: 4245-4302.

MORÍNIGO, M. A. (1998). Nuevo diccionario de americanismos e indigenismos. Buenos Aires: Claridad.

OESTERREICHER, W. (2004). "Textos entre inmediatez y distancia comunicativas. El problema de lo hablado escrito en el Siglo de Oro" en Historia de la lengua española. (Coord. R. Cano Aguilar). Barcelona: Ariel: 729-770.

RAMÍREZ LUENGO, J. L. (2007). Breve Historia del Español de América. Madrid: Arco Libros.

REAL ACADEMIA ESPAÑOLA/ASALE (2009). Nueva Gramática de la Lengua Española. Madrid: Espasa.

TOGNOLA, D. (2010). Variaciones y constancias en algunos usos de nomás (Tesis de maestría inédita). Bariloche: Universidad Nacional de Río Negro. 